\title{
Petroleum Resource Exploration System: As the Dongying Depression, Bohai Bay Basin, China
}

\author{
Yang Wang ${ }^{1}$, Yongqiang Yang ${ }^{1, *}$, Jiaqiang Luo $^{2}$ and Bateer Chen ${ }^{1}$ \\ ${ }^{1}$ State Key Laboratory of Geological Processes and Mineral Resource, China University of \\ Geosciences, Beijing 100083, China \\ ${ }^{2}$ Institute of Oil \& Gas, Peking University, Beijing 100087, China
}

\begin{abstract}
Bohai Bay Basin is a hot area for research marine petroleum. Petroleum System is an important method to study petroleum. However, facing on more complicated middle-high graded petroleum exploration area, formerly elements of the Petroleum System are not enough to cover all factors. Hydrocarbon was controlled by main migration path, additionally the complicated mechanism and controlling factors in a formed oil-gas pool are carefully considered. We put "track down (oil-gas reservoir) by following clues (the main migration path of petroleum)" based on the Dongying Depression data, and drill the best of all targets for oil-gas reservoir on the condition of revealing oil resource. The venture of petroleum exploration can be reduced farthest, and the benefit of petroleum exploration can be increased farthest by the method.
\end{abstract}

\section{Introduction}

Recent decades have witnessed an increasing number of studies investigating the Petroleum Systems [1-9]. The petroleum system is a unifying concept that encompasses all of the disparate elements and processes of petroleum geology. Practical application of petroleum systems can be used in exploration, resource evaluation, and research. A petroleum system encompasses a pod of active source rock and all genetically related oil and gas accumulations. It includes all the geological elements and processes that are essential if an oil and gas accumulation is to exist. Petroleum system describes the dynamic characteristics of the system, focuses on hydrocarbon producing potential and oil migration and accumulation processes; based on the dissection of exemplary reservoirs, analyse producing and reservoir and cap configuration, as well as filling process, studies reservoir layer type and geometrical shapes, predicts exploration zone utilizing geophysical technology, makes scientific appraisal of resource potential and exploration prospect.

There are a lots of barriers and disturbances in the petroleum exploration process, the weakest link in the petroleum geologic research and petroleum exploration of the middlehigh-exploration-level area in the continental basin is that whether the implement the trap is oily, whether the reservoirs have formed, how well is the reserves and whether it is worth drilling. We put "track down (oil-gas reservoir) by following clues (the main migration path of petroleum)" based on the Dongying Depression data.

\footnotetext{
* Corresponding author: yangyongq@cugb.edu.cn
} 


\section{Effective hydrocarbon sources}

In recent years, with the drilling of deep wells in oil-depressions, core blocks of deep source rocks get increased, so that it has been equipped with the intensive study of hydrocarbon source rocks and because of the introduction and application of domestic and foreign advanced equipment and analytical techniques, it became possible to study hydrocarbon source rocks systematically and in depth; at the same time, based on the improvement of organic geochemical analysis techniques for hydrocarbon source rock evaluation and the in-depth study on hydrocarbon source rocks, oil and source correlation and reservoir forming, it has made great achievements in reservoir formation and hydrocarbon formation, such as low mature oil, effective hydrocarbon source rocks, highquality hydrocarbon source rocks and secondary hydrocarbon generation and so on. The effective hydrocarbon source rocks are the ones which have contribute to the formation of oil and gas reservoirs with industry value and can be distinguished primarily through oil and source correlation. The spatial distribution characteristics and the main period of hydrocarbon expulsion of effective hydrocarbon source rocks are the important contents of accurate oil and gas exploration method.

\subsection{Spatial distribution of effective hydrocarbon source rocks}

Usually, the spatial distribution of effective hydrocarbon source rocks in continental basins is under the control of basin type, the central sediment, sedimentary facies, provenance, hydrodynamic conditions, the thermal evolution, etc [2-4]. The developing stratum and spatial distribution of effective hydrocarbon source rocks directly control the location, size and accumulation model of the oil and gas reservoir. The developing stratum of effective hydrocarbon source rocks can be distinguished through a large number of organic geochemical analysis of data and oil and source correlation; while its spatial distribution can be studied with the help of a lot of drilling, logging, and data of multi-well constrained seismic inversion. The structure contour map and thickness contour map about top and bottom of effective hydrocarbon source rocks are important to reflect the spatial distribution of effective hydrocarbon source rocks, the types of the main hydrocarbon migration pathway and the direction of lateral migration pathway.

\subsection{Hydrocarbon expulsion of effective hydrocarbon source rocks}

During the constant procession of burial, compaction and diagenesis of the effective hydrocarbon source rocks, it comes up that hydrocarbon formation of organic matter, inorganic mineral transformation and dehydration, change of rock structure and so on, and these will all lead to the hydrocarbon expulsion $[5,6]$. Therefore, the main driving force of hydrocarbon expulsion of the effective hydrocarbon source rocks is the internal fluid pressure which comes from the compaction, fluid generation and geothermal stress, and these effects are of different sizes in different stages of evolution. Usually, during the early diagenesis, because of the high porosity of source rocks, sustained compaction can emit a large number of hydrocarbon fluids; while in the late diagenesis, the compaction is close to the limit so that the change of porosity is very small, and therefore the main reason for a large number of hydrocarbon expulsion is the hydrothermal fluid generation and hydrothermal pressurization. In short, the hydrocarbon generation and expulsion of effective hydrocarbon source rocks is mainly a non-continuous process related to periodic tectonic activities, with a curtain-type characteristic of hydrocarbon expulsion. And the start time and main period of hydrocarbon expulsion can be defined through the basin modelling study. The hydrocarbon expulsion intensity contour maps of effective hydrocarbon source 
rocks are important to reveal the condition of one main migration pathway, such as the quantity of oil and gas transportation, the location and size of hydrocarbon-bearing pools that it forms.

\section{Main migration pathway}

The migration paths of petroleum are determined by the three-dimensional spatial distribution of discontinuities closed-surface (usually parallel to bedding plane) in petroliferous basins. The oil and gas migrating along the main pathway is the most favorable and has the least structural resistance below the closed surface choose structure, migration path of - the main migration channel migration, in which structural shape, faults or cracks with long-term or many periods of the activities. The reservoir with high porosity and permeability and planes of unconformity play a major role in controlling the main migration pathway.

\subsection{Basic elements of main migration pathway}

The basic elements of the main migration pathway are faults, framework sand bodies and planes of unconformity in petroliferous basins. Usually, oil and gas migrate for a short distance horizontal along the framework sand bodies, for a long distance lateral along the planes of unconformity and vertical along the faults and fracture systems. The main migration pathway rising up in the mixed mode, in particular, it is common that two of the faults, framework sand bodies and planes combine with each other, or even all of them combine. From the hydrocarbon source rock to the trap, the main migration pathway develop gradually from divergence to convergence, from small to thick, from many to few in a shape of "inverted tree branch" based on the Dongying Depression data.

Faults and fractures, have been recognized that the faults are the main vertical migration pathway of oil and gas by scholars at home and abroad, which is often through the different strata of the source rocks and reservoir rocks. When the faults are active, they are the pathways for oil and gas; while the faults are inactive, then the block for them. The pathway and block are relative and can be transformed to each other due to certain condition. Faults and cracks are transverse, can take long-distance vertical migration and the migration is periodical. Growth fault and fractures have a very important significance on oil and gas migration and accumulation in continental basins, especially the continental faulted basins with mature faults. When studying the relationship between hydrothermal deposit and ancient faults. According to the relationship between fault active stage and the oiliness, when the fault activity stage was in accordance with the stage of hydrocarbon generation and migration, the fault was conducive to the oil and gas migration along faults and fissures, and the accumulative amount of the fluids was different along the fault strike, which indicated that the morphology of fault surfaces play an important role in the control of the oil and gas migration. Therefore, the faults and cracks, in particular which cut through effective hydrocarbon source rocks, are important parts of the main petroleum migration pathway.

Framework sand bodies, we considered that when the oil and gas migrated from the hydrocarbon source rocks into the framework sand bodies, the direction of its migration was significantly affected by the horizontal permeability of migration. The framework sand bodies of the river and delta which have good porosity and permeability is the main lateral petroleum migration pathway for a short distance. In general, the framework sand bodies for horizontal migration and the (oil source) fault. 


\subsection{Main migration pathway location}

The main migration pathway of oil and gas is controlled by the three-dimensional geometric shape of the pathway's top surface or the under surface of cap rocks. The oil and gas migration paths form a dense network near the hydrocarbon generation depression; while far from the depression, they converge to form the main hydrocarbon migration pathway. It is because that oil and gas migration is not equivalent and emanative in threedimensional space, but is limited in a certain path, that the dispersive oil and gas expulsed form hydrocarbon source rocks can migrate, aggregate and accumulate. The oil and gas migration can be considered as a strictly bound "river" or "stream" which mainly consists of the faults, cracks, framework sand bodies, planes of unconformity or a combination of them, and only the carrier bed of $1 \% \sim 10 \%$ cross sectional area can be used. The migration paths come together only when the sealing surface is arch shape or anticline-like. Thus, the location of the main petroleum migration pathway macroscopically are the area with a anticlinal sealing surface, such as framework sand bodies and planes of unconformity with good physical properties which has non-tectonic setting or a simple tectonic setting such as monocline, structure ridges which consist of framework sand bodies and planes of unconformity with good physical properties, the convexity of faults and so on.

Structure ridges, the structure ridges which consist of framework sand bodies and planes of unconformity are the important paths for the migration and accumulation of oil and gas, such as the nose-like structure or ridge lines of anticline [7,8]. When the oil and gas are expulsed from the hydrocarbon source rocks, they migrate along the structure ridges under the buoyancy, hydrodynamic and capillary forces until the ridge has been blocked, and then form the reservoirs. The structure ridges in top structure maps of framework sand bodies and planes of unconformity are the locations of the main petroleum migration pathway. The (horizontal and vertical) migration paths of oil and gas all follow the simple geometric rules, which can be predicted. Lateral migration path is decided by the porosity and permeability of the rock; while the path of vertical migration is mainly decided by fracture and cracks which are the main factors affecting the distribution of oil and gas, and have important significance in the accumulation and exploration of oil and gas. In accurate oil exploration, the geometrical characteristics and location of the oil and gas migration path are very important. Once they are determined, the most prospective traps can be determined in or near the path so as to reduce the scope of exploration and the risk and improve the benefit.

\subsection{Geometrical description of main migration pathway}

Oil and gas can take vertical and horizontal migration of which the paths follow simple geometric rules. Therefore, the main hydrocarbon migration pathway can be predicted. Lateral migration path is decided by the porosity and permeability of the rock; while the path of vertical migration is mainly decided by fracture and cracks which are the main factors affecting the distribution of oil and gas, and have important significance in the accumulation and exploration of oil and gas. In accurate oil exploration the geometrical characteristics and location of the oil and gas migration path are very important. Once they are determined, the most promising exploration targets - oil and gas reservoirs can also be determined in or near the path and then the drilling can be put into effect. In the area of middle-high exploration level in petroliferous basins, there is abundant 3-D seismic and drilling wells data, etc., which provide favorable conditions for the study and description of the main migration pathway. At the same time, the seismic interpretation techniques, extensive computer applications and 3-D visualization technology make it possible and can be displayed visually and intuitively. The morphology description of fault plane: earthquake constrained inversion techniques and seismic multi-attribute analysis techniques 
are powerful tools to find out morphology, occurrence and composition relation of the fracture, so as to determine the main hydrocarbon migration pathway. While the extensive applications of drilling, logging data makes the study on the morphology of fault plane more credible.

\section{Formation and evolution of traps}

The trap is a 3-D geologic body which can accept and pool oil for quite a long time, which is the product affected by a number of factors such as tectonic movements and deposition and has an important meaning of time [9]. The traps which form simultaneous with or before the expulsion of effective hydrocarbon source rocks are effective traps so as to accept the oil and gas accumulation, while the corresponding trap volume basically determines the limit of reservoir-scale. In addition, late tectonic movements will change and destroy the formed traps, which lead to the change of trap shape, volume, the accumulative oil and gas. Therefore, only the trap which has the same time as oil and gas migration and is in or near the main hydrocarbon migration pathway can form oil and gas reservoirs. The formation and evolution of the trap is the important research content. The top surface structural contour map of traps is the important result map of the trap research. Research of trap formation and evolution research is mainly done through the analysis of structural history.

According to former research, the accumulation of effective hydrocarbon source rocks is a continuous process with hydrocarbon-generating peak. The hydrocarbon expulsion is not continuous, but episodic, which is associated with periodic tectonic activities. In basic elements of the main migration path, the fault is the only one which is episodic. Therefore, the fault active period is often the main period of the episodic hydrocarbon expulsion and petroleum migration. The fracture or crack is the main migration pathway through which hydrocarbon can migrate extensively and efficiently; and the hydrocarbon migration through framework sand bodies and unconformity planes which contact the hydrocarbon source rocks varies along with the hydrocarbon generation.

To sum up, based on the study of the effective hydrocarbon source rocks and its expulsion characteristics, the basic elements, path and geometry description of the main hydrocarbon migration pathway, as well as the formation and evolution of traps, we can further determine the most promising exploration targets - oil and gas reservoirs in or near the path and then the drilling can be put into effect. According to the model diagram of "source - migrate - accumulate" in accurate oil and gas exploration methods, that studying targeted to the "source - migrate - accumulate" of different geological backgrounds can maximally reduce the exploration risks in basins.

The final result map of accurate oil and gas exploration is a comprehensive map which includes top surface structure contour map of effective hydrocarbon source rock, structure contour map of the morphology of faults, framework sand bodies and plane of unconformity, physical properties contour map of framework sand bodies, top surface structural contour map of traps, and so on.

\section{Conclusions}

We put Main Migration Path Controlling Hydrocarbon theory based on the Dongying Depression data, it is revealing oil generation first and then selecting zone for exploration and rolling exploration and development. This theory is suitable for area with mid-high exploration level. With a precondition for the source setting and the use of rich seismic data, measured (recorded) Well, core block, analysis and test data, dynamic data of production 
and a large number of preliminary research results, the accurate methods describe the surface geometry and spatial distribution of the main oil and gas migration pathway faults, framework sand bodies and unconformity plane in detail, define the geometrical shape and distribution of the main petroleum migration path, figure out the formation time and distribution of traps, and drill the best of all targets - oil and gas reservoir on the condition of revealing oil resource. The accurate oil and gas exploration method can make obvious effects in oil-gas exploration, and maximally reduces the exploration risks in the areas of the continental basins with mid-high level exploration and increase the exploration benefits. By using the theory of Main Migration Path Controlling Hydrocarbon and combining with the exploration method of track down by following clues (what kinds of the clues), the drilling risks can be reduced due to the improvement on entrapment understanding. Therefore, it raised the achievement greatly in the petroleum exploration. At same time, this method can contribute to improving the environmental situation in the process of oil exploration.

\section{References}

[1] Harris E J (1981). Production geology North Rankin gas field//Halbouty M T.Energy Resources of the Pacific Region. APG Studies in Geology, 12:273-283.

[2] Pepper A S (1991). Estimating the petroleum expulsion behaviour of source rocks: A novel quantitative approach. Geological Society, London, Special Publication, 59(1): 9-15.

[3] Thomas G P, Lennane M R, Glass F (2004). Breathing new life into the eastern Dampier Sub-basin: An integrated review based on geological, stratigraphic and basin modeling evaluation. APPEA Journal, 4:123-150.

[4] Luo K P, Zhou Z Y and He Z L (2007). Application and development of petroleum system in China Basins. Petroleum Geology \& Experiment, (2):31-38.

[5] Pollastro R M (2007). Total petroleum system assessment of undiscovered resources in the giant Barnett Shale continuous (unconventional) gas accumulation, Fort Worth Basin, Texas. AAPG Bulletin, 91(4): 551-578.

[6] Wang J Y, Shi S M and Du X L (2014). Beier Depression Petroleum System Study in Hailaer. Applied Mechanics and Materials, 668-669,1546-1549.

[7] Montes C, Rodriguez-Corcho A F, Bayona G, Hoyos N, Zapata S, and Cardona A (2019).Continental margin response to multiple arc-continent collisions: the northern Andes-Caribbean margin. Earth Sci. Rev., 198, p. 19, 10.1016/j.earscirev.2019.102903

[8] Zhao X Z, and Pu X G (2019). An exploration breakthrough in Paleozoic petroleum system of Huanghua Depression in the Dagang Oilfield and its significance, North China. Petroleum Exploration and Development (4):11-18.

[9] Carvajal-Arenasab LC, Torradoab L, Manna P, and English J (2020). Basin modelling of Late Cretaceous / Mio-Pliocene petroleum system of the deep-water eastern Colombian Basin and South Caribbean Deformed Belt. Marine and Petroleum Geology, 121,104511. 